\title{
Factors associated with participation of Alberta dairy farmers in a voluntary, management-based Johne's disease control program
}

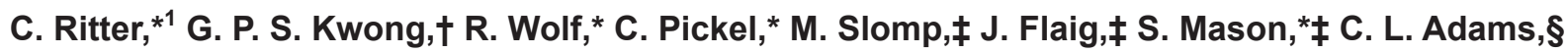 \\ D. F. Kelton,\# J. Jansen,II J. De Buck, ${ }^{*}$ and H. W. Barkema* \\ *Department of Production Animal Health, Faculty of Veterinary Medicine, and \\ †Faculty of Veterinary Medicine, University of Calgary, T2N 4N1 Calgary, AB, Canada \\ $\ddagger$ Alberta Milk, T6X 1H1 Edmonton, AB, Canada \\ $\S$ Department of Veterinary Clinical and Diagnostic Sciences, Faculty of Veterinary Medicine, University of Calgary, T2N 4N1 Calgary, AB, Canada \\ \#Department of Population Medicine, Ontario Veterinary College, University of Guelph, N1G 2W1 Guelph, ON, Canada \\ IISt. Anna Advies, 6525 ZM Nijmegen, the Netherlands
}

\section{ABSTRACT}

The Alberta Johne's Disease Initiative (AJDI) is a voluntary, management-based prevention and control program for Johne's disease (JD), a wasting disease in ruminants that causes substantial economic losses to the cattle industry. Despite extensive communication about the program's benefits and low cost to participating producers, approximately $35 \%$ of Alberta dairy farmers have not enrolled in the AJDI. Therefore, the objective was to identify differences between AJDI nonparticipants and participants that may influence enrollment. Standardized questionnaires were conducted in person on 163 farms not participating and 61 farms participating in the AJDI. Data collected included demographic characteristics, internal factors (e.g., attitudes and beliefs of the farmer toward JD and the AJDI), external factors (e.g., farmers' JD knowledge and on-farm goals and constraints), as well as farmers' use and influence of various information sources. Nonparticipants and participants differed in at least some aspects of all studied categories. Based on logistic regression, participating farms had larger herds, higher self-assessed knowledge of JD, better understanding of AJDI details before participation, and used their veterinarian more often to get information about new management practices and technologies when compared with nonparticipants. In contrast, nonparticipants indicated that time was a major on-farm constraint and that participation in the AJDI would take too much time. They also indicated that they preferred to wait and see how the program worked on other farms before they participated.

Key words: extension, communication, attitude, behavior, Johne's disease

Received May 6, 2015.

Accepted July 15, 2015.

${ }^{1}$ Corresponding author: cmnritte@ucalgary.ca

\section{INTRODUCTION}

Johne's disease (JD) is an infectious chronic enteritis caused by Mycobacterium avium subspecies paratuberculosis (MAP). Symptoms in dairy cattle include intermittent diarrhea, loss of body condition, and reduced milk production (Tiwari et al., 2006). In the absence of an effective cure, affected animals eventually die or are culled due to poor condition. With approximately $70 \%$ of Alberta dairy herds being infected with MAP (Wolf et al., 2014a), JD leads to substantial economic losses for individual farmers and the Canadian dairy industry (Wolf et al., 2014b). Furthermore, JD may also be associated with Crohn's disease in humans (Barkema et al., 2011). A causal link between JD and Crohn's disease, or even the perception that MAP is a health risk to humans, could have a considerable negative effect on the dairy industry (Groenendaal and Zagmutt, 2008; Barkema et al., 2011).

Preventing disease introduction into a herd, reducing infections of calves, and not using contaminated equipment are currently the best practices to decrease transmission of MAP (Sweeney et al., 2012; Barkema et al., 2014); however, implementation of these control measures requires behavioral changes by producers. To increase uptake of control strategies for JD and to provide province-wide standards, the Alberta Johne's Disease Initiative (AJDI) was launched in 2010 (Wolf et al., 2014b). The AJDI is a voluntary, managementbased control program; its primary purposes are to make farmers more aware of JD and to decrease disease prevalence. As part of the AJDI, MAP status of participating farms is assessed annually, based on environmental fecal samples. Prior to program enrollment, dairy farmers are generally unaware of their status because private testing for MAP is uncommon. On-farm risk assessments are another important aspect of the program; veterinarians trained for AJDI administration 
identify critical management practices and develop a herd-specific management plan to reduce the risk of MAP transmission.

Despite comprehensive extension efforts and the low cost of the program to participants, 35\% of Alberta's approximately 580 dairy farms were not enrolled in the AJDI at study initiation in 2012 (Wolf et al., 2014a).

Why some farmers do not implement suggested management practices to improve animal health, although it would be apparently beneficial, has become an important area of research (Ellis-Iversen et al., 2010; Jansen and Lam, 2012). In recent years, several theories have been developed to understand and predict human behavior (Coleman and Pasternak, 2012). Two of the most widely used frameworks in health behavior research are the health belief model (Janz and Becker, 1984) and the theory of planned behavior (Ajzen, 1991). The former concludes that attitudes toward a disease (e.g., does the farmer perceive the disease as a problem), as well as the perceived effectiveness of the proposed strategy to overcome the disease, are key factors for behavioral change (Jansen and Lam, 2012), whereas the latter regards attitudes toward the behavior, subjective norms, and perceived self-efficacy as important influences on intentions to change behavior (Ajzen, 1991).

Since their development, both models have been adapted numerous times, according to specific research questions. One example of a framework that draws from previous theories is the social ecology model (Panter-Brick et al., 2006) that was modified and used for the purpose of this study (Figure 1). This model has previously been validated by Ellis-Iversen et al. (2010) to identify and explain motivational factors for implementation of disease control programs on cattle farms. According to the model, farmers' decision-making process depends on intrinsic and extrinsic factors (Ellis-Iversen et al., 2010). Intrinsic factors consist of farmers' attitudes, beliefs, and norms. For this study, intrinsic factors relate to farmers' evaluation of JD and the proposed approach to overcome it. Extrinsic circumstances include resources that the farmer has available to make changes. Herein, extrinsic factors include farmers' knowledge about JD, their skills and abilities, but also disabling factors such as limited time or economic constraints. If farmers' intrinsic or extrinsic factors are not favorable toward JD or the AJDI, these factors constitute barriers hampering enrollment and hence uptake of risk-reducing behavior (Ellis-Iversen et al., 2010).

Because preferred sources of information varied among farmers (Russell and Bewley, 2011; Garforth, 2012; Brennan and Christley, 2013), another potential impediment for enrollment is that external stimuli such as applied extension strategies have been ineffective in reaching and educating some farmers about the AJDI and advantages of participation. The objectives of the

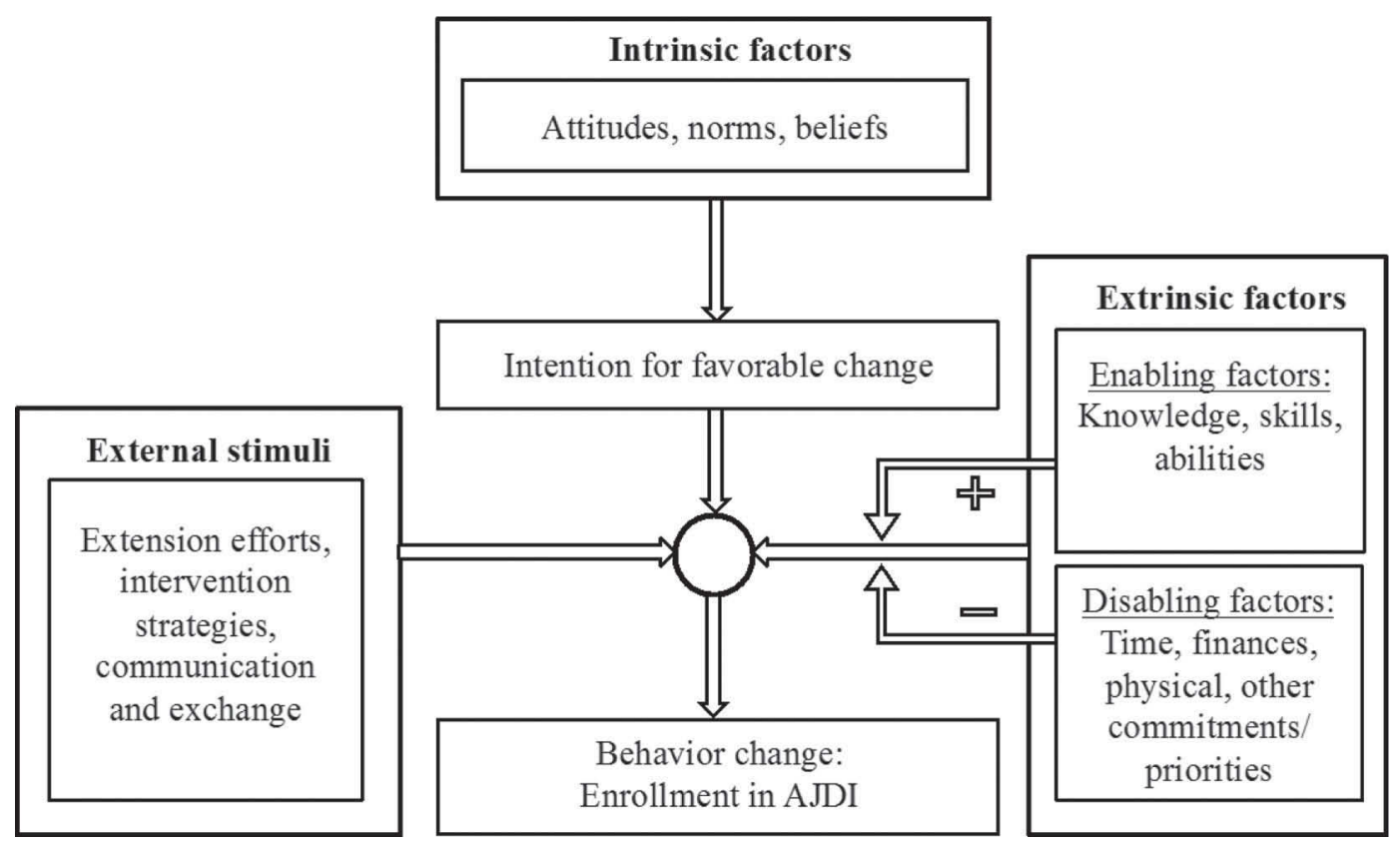

Figure 1. Study framework used to assess factors associated with enrollment in the Alberta Johne's Disease Initiative (AJDI; adapted from data in Panter-Brick et al., 2006; Ellis-Iversen et al., 2010). 
study were, therefore, to compare AJDI participants and nonparticipants with regard to (1) general demographics, (2) intrinsic characteristics toward JD and JD control, (3) extrinsic factors, and (4) external stimuli.

\section{MATERIALS AND METHODS}

\section{Herds and Questionnaire}

Alberta dairy farmers living within $350 \mathrm{~km}$ of Calgary, Alberta, Canada, were eligible for the study (i.e., 179 $(86 \%)$ of all nonparticipating farms and $353(94 \%)$ of all participating farms). Between September 2012 and April 2014, all eligible nonparticipants and, due to time and budget considerations, a randomly selected sample of 69 participants were contacted by telephone. One hundred sixty-three (91\%) of the contacted nonparticipants as well as $61(88 \%)$ of the contacted participants agreed to be surveyed. Reasons for refusal were time constraints, illness, travel, or lack of interest. A farm visit was scheduled with each farmer to be interviewed; those interviewed were responsible for herd management and decision making on their farms.

A questionnaire to be used in the interviews was designed, taking into account current knowledge regarding JD and factors influencing farmers' mindset and uptake of preventive measures. A team of extension specialists, veterinary epidemiologists, and veterinary practitioners developed a pilot questionnaire, based on their expertise and relevant literature, which was tested on 13 participating and 10 nonparticipating farms. Feedback was received with regard to content and clarity. Farmers that provided feedback were afterward excluded from the study, and pilot surveys were not included in the analysis. After adjustment, the final questionnaire, containing 38 questions, addressed the following topics: (1) general demographics, (2) intrinsic factors toward JD and the AJDI (i.e., farmers' attitudes, beliefs, and norms), (3) extrinsic factors (i.e., main on-farm goals and constraints, as well as farmers' self-assessed knowledge of JD), and (4) external stimuli (i.e., use and influence of information sources; see Supplemental files; http://dx.doi.org/10.3168/jds.2015-9789). Possible answers to the questions consisted of order rankings, factual assessments, yes/no replies, and 5-point Likert items (Likert and Hayes, 1961). Face-to-face interviews were conducted by 4 trained interviewers on the producers' farms. The farmer received a hard copy of the survey to read, while the interviewer read the questions aloud and documented the farmer's answer. To minimize variability, interviewers were trained to conduct the surveys in a neutral manner. On average, $30 \mathrm{~min}$ was required to complete the questionnaire.

\section{Statistical Analyses}

Each of the 4 themes of the questionnaire (i.e., general demographics, intrinsic factors, extrinsic factors, and external stimuli) was first investigated separately for associations between various predictors and the outcome. Thereafter, a final logistic regression model, which consisted of variables from the 4 themes, was developed.

For analysis of the 4 primary themes, levels of a variable were combined if the number of participants or nonparticipants was $<5$ (to avoid unstable parameter estimates). Before entering variables in multivariable regression analyses, collinearity between variables within a theme was assessed using Pearson correlation coefficient for continuous variables and Kendall's tau-b for ordinal variables. If 2 variables were highly correlated $(|\mathrm{rho}| \geq 0.7$ in continuous case or $\mid$ tau-b $\mid \geq 0.3$ in ordinal case), only 1 was retained, based on interpretability, missing data, and correlation with other variables.

List-wise deletion within models was used (i.e., observations of a farmer were only deleted for a particular model in case of missing data relevant to that model, although the farmer could still provide information for another model).

Distribution of the number of responses for each variable level was assessed, and the level on either end of the scale (e.g., 1 or 5) with the higher frequency in responses was selected as reference level for regression model analyses. Variables for individual multivariable regression models were selected based on univariable association with participation at $P<0.20$. Variables for the final model were selected based on $P<0.02$ in the Wald test of the respective model. Interaction terms were included in the final model and collinearity between variables was assessed, applying the same criteria as mentioned above. Manual backward elimination was used to identify the most significant predictors of participation in each multivariable regression model. In detail, the variable with the highest $P$-value in the Wald test (Stata command: test) was excluded from the model, given that $P>0.05$ in every level of that particular variable. Additionally, the remaining variables were assessed for confounding (i.e., a 30\% change in the estimate) by the removed variable. If confounding was present, the variable remained in the model. This procedure was continued until (1) no predictor had $P$ $>0.05$ in the Wald test; (2) no level of a variable was $P>0.05$; or (3) the likelihood ratio test comparing the full model with the reduced model was $P<0.05$ (in this case, the last removed variable was inserted back into the regression model). Demographic variables with $P<$ 0.20 were considered as confounders in every multivariable logistic regression model. 
A probability level of $P<0.05$ was considered significant. Principal component analysis was performed in SPSS (IBM Statistics, Version 22 for MacOSX, Armonk, NY), and all other statistical analyses were done in Stata 12.1 (Stata Corp., College Station, TX).

General Demographics. Number of lactating cows, current average bulk tank SCC, and daily production per cow were deemed continuous variables (subsequent natural logarithmic transformation ensured a normal distribution). Categorical classification of age of producer (cut points: $\leq 30,31-40,41-50,>50 \mathrm{yr}$ ), years of experience as dairy producer (cut points: $\leq 10,11-20$, $21-30,>30 \mathrm{yr})$, years until retirement $(<3$, within $3-5$, within $5-10,>10 \mathrm{yr}$ ), and education (cut points: $\leq 12$ yr, college diploma, university degree) were used for analysis.

Intrinsic Factors. Data on beliefs, norms, and attitudes toward JD and AJDI were collected using statements that farmers rated on 5-point Likert items (Likert and Hayes, 1961). For example, AJDI participants and nonparticipants were asked to express their agreement to statements such as "Reducing JD prevalence may help protect the Canadian dairy industry," or their concern about JD "How much does JD worry you"? A total of 28 Likert items were included to explore intrinsic factors in the questionnaire.

Data analysis for intrinsic factors was based on 3 steps: (1) principal component analysis (PCA) was used to reduce the number of variables in the data set and to reduce multicollinearity among variables; (2) univariable logistic regression analyses was performed to assess associations between the reduced data set and participation status; and (3) multivariable logistic regression was carried out to include variables with $P$ $<0.20$ from univariable analyses.

First, a correlation matrix was generated and variables with high singularity were excluded. Multicollinearity among the remaining variables was assessed based on the determinant of variance, with a threshold of $>0.0001$ to ensure suitability of the data set for PCA (Field, 2005). Adequacy of the data set was further examined by assessing the overall Kaiser-Meyer-Olkin measure of sampling adequacy (KMO) and individual KMO values based on a threshold of 0.5 , as well as Bartlett's test of sphericity (Field, 2005). Extracted components were selected based on inspection of the scree plot, the total amount of variance explained, and eigenvalues >1 (Kaiser, 1960; Dohoo et al., 1997). Because correlation between components could not be excluded, direct oblimin rotation was applied to facilitate interpretability (Field, 2005). Component loadings $>|0.35|$ were used in interpretation of extracted components. A test for reliability using Cronbach's $\alpha>0.7$ as the threshold value (Field, 2005) was done to assess internal consistency of each extracted component.

Second, univariable logistic analysis was performed to identify predictor variables that were associated $(P<0.20)$ with participation in the AJDI. Predictor variables tested in univariable analysis included components extracted through PCA and independent discrete intrinsic variables that were not compromised in any component.

Third, all intrinsic factors identified in step 2 were included in the multivariable logistic regression analysis and a stepwise logistic regression (with backward elimination) was done to identify differences between nonparticipants and participants.

Extrinsic Factors. Producers were asked to identify their largest on-farm goals and constraints by selecting the 3 choices most relevant to them (from 8 or 9 possibilities, respectively), and rank their answers. Data for these rank order questions were analyzed by assigning 3 points to the first-choice item, 2 points to the second-choice item, and 1 point to the third-choice item. Dummy variables were created for on-farm goals and constraints, and rankings 1 to 3 were compared with the baseline of not being among the top 3 items. Variables with a $P<0.20$ from the Mann-Whitney $\mathrm{U}$ test or from the univariable logistic regression analysis were included in the extrinsic multivariable logistic regression model.

To evaluate self-assessment of JD knowledge, farmers were asked to respond to several statements regarding JD (e.g., "I know the clinical signs of JD" or "I know the general transmission of the disease") by answering yes or no. Differences between participants and nonparticipants with regard to each statement were tested using chi-squared or Fisher's exact tests on contingency tables. Knowledge was then included in the logistic regression model as a summary measure by summing positive responses (i.e., yes) for every farmer.

External Stimuli. How often farmers used various information sources to obtain information about new management practices and technologies was assessed on 5-point Likert items. Scores of 1, 3, and 5 indicated that the farmer never, sometimes, and always used the particular source, respectively. Similarly, 5-point Likert items were used to assess what information sources influenced AJDI participation. A score of 1 meant a particular source influenced AJDI enrollment very negatively, whereas a score of 5 meant a particular source had a very positive influence on AJDI enrollment. Here, the farmer also had the option to choose not applicable if no information was received from a particular source (as opposed to a score of 3 where information was received from the source, but did not have any influence 
on AJDI participation). Logistic regression was used to assess whether use or influence of various information sources was associated with participation in the AJDI.

Final Model. To select the most relevant variables for the final model, all covariates with a significant association with participation in any of the previous multivariable logistic regression models were considered. To limit the number of variables in the final model, only variables with $P<0.02$ in the Wald test were included. Interaction terms were generated and backward elimination was done.

\section{RESULTS}

\section{General Demographics}

The AJDI participants had more lactating cows compared with nonparticipants (median of 90 and 120, respectively; Table 1). Nonparticipants intended to retire earlier compared with participants; in that regard, $20(12 \%)$ of the nonparticipants and $2(3 \%)$ of the participants intended to retire within the next 5 yr. Age of the farmer was highly correlated with years until expected retirement and years as a dairy producer (tau-b $=-0.52$ and 0.74 , respectively). Similarly, years until expected retirement was highly correlated with years as a dairy producer (tau-b $=-0.48)$. Based on the small $P$-value and biological plausibility, years until retirement stratified into 2 groups was selected for multivariable regression analysis.

\section{Intrinsic Factors}

Using PCA was supported by the absence of extreme multicollinearity (determinant of variance $=0.02$ ) and individual KMO values in the anti-correlation matrix of $>0.65$. Also, an overall KMO of 0.793 resulted in a significant Bartlett's test of sphericity ( $\sim$ chi-squared $=713 \mathrm{df}=78, P<0.001)$. Selection of components based on eigenvalues $>1$ and inspection of the scree plot initially resulted in 4 multi-item measures. However, the fourth component failed the test for reliability (Cronbach's $\alpha=0.62$ ), and was therefore excluded from further PCA analysis. The 3 remaining components explained $55 \%$ of the variance and represented distinct aspects of intrinsic factors that were associated with AJDI participation (Table 2). Component 1 represented farmers' general perception of the consequences

Table 1. Farm and producer characteristics of 61 farms that participated and 163 farms that did not participate in the Alberta Johne's Disease Initiative between September 2012 and April 2014

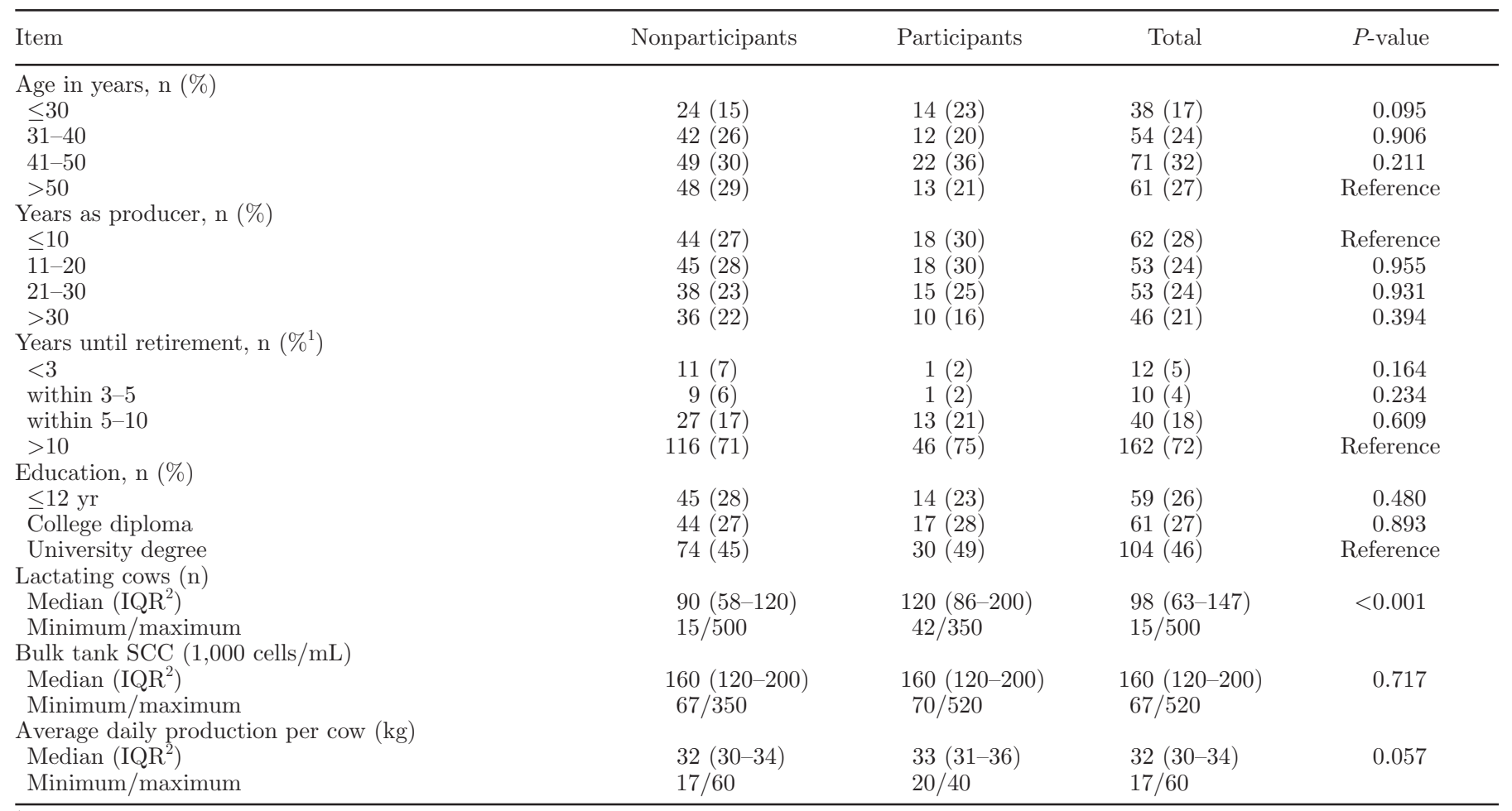

${ }^{1} P=0.046$ comparing retirement within $\leq 5 \mathrm{yr}$ and $\geq 5 \mathrm{yr}$.

${ }^{2}$ Interquartile range. 
Table 2. Loadings of Johne's disease (JD) statements of 61 farmers participating (P) in the Alberta Johne's Disease Initiative (AJDI) and 163 nonparticipating farmers (NP) on principal component analysis components ${ }^{1}$

\begin{tabular}{|c|c|c|c|}
\hline Item & \multicolumn{3}{|c|}{ Component } \\
\hline Dairy industry is taking a proactive approach to manage wJD $\left(\mathrm{Q} 27^{2}\right)$ & 0.552 & & \\
\hline $\begin{array}{l}\text { Dairy product consumption will decrease if a link between } \mathrm{CD}^{3} \text { and JD is proven } \\
\text { or portrayed negatively (Q26) }\end{array}$ & 0.787 & & \\
\hline Danger of link between JD and CD to dairy industry (NP: Q33d, P: Q34d) & 0.713 & & \\
\hline Importance that the AJDI is low cost (NP: Q33a, P: Q34a) & & 0.881 & \\
\hline $\begin{array}{l}\text { Importance that risk assessment and new management practices do not take much } \\
\text { time (NP: Q33b, P: Q34b) }\end{array}$ & & 0.879 & \\
\hline How much of an issue is JD for your farm (Q20b)? & & & 0.865 \\
\hline
\end{tabular}

${ }^{1}$ Loadings $>|0.35|$ are displayed. Interviews were conducted between September 2012 and April 2014.

${ }^{3}$ Number of question in survey.

${ }^{4}$ Crohn's disease.

of JD for the dairy industry. Component 2 was highly correlated with the importance of minimal cost and time investments for AJDI participation. Component 3 represented farmers' concern and worry about JD.

Univariable regression analyses resulted in associations $(P<0.20)$ with AJDI participation of components 1 and 3, as well as 14 additional discrete intrinsic variables not included in any of the components (Supplemental Table S1; http://dx.doi.org/10.3168/ jds.2015-9789).

Results from the multivariable logistic regression model consisted of 7 intrinsic variables that were associated with participation (Table 3). The most central findings when comparing AJDI nonparticipants and participants (who were asked to answer retrospectively before they participated) were that nonparticipants agreed more strongly that new management practices would take too much time, the costs of the AJDI would outweigh the benefits, and control of other diseases was more important to them. Compared with participants before enrollment, nonparticipants more often did not know if they expected their herd to be infected with MAP. Nonparticipants more often neither agreed nor disagreed with the statement that they understood AJDI details well, whereas participants, answering retrospectively, more often strongly disagreed. Also, nonparticipants agreed more strongly with the statement that animal trade and export will be unaffected by JD, and it was more important to them to know that the AJDI "has worked" on other farms.

\section{Extrinsic Factors}

Nonparticipants and participants in the AJDI most often ranked "improve herd health," "increase herd longevity," and "increase net profit" among their top 3 goals on their farms (Table 4). Time, financial resources, and facilities were the most common constraints selected in both groups. Participants perceived their knowledge of JD overall as better compared with nonparticipants (Table 5), although both groups stated that they generally know that JD exists. Furthermore, $>50 \%$ of producers in both groups were familiar with the clinical signs of JD, some issues with controlling JD, the general transmission of the disease, and ages of greatest susceptibility. Besides the difference in self-assessed knowledge, multivariable logistic regression revealed that improved herd health was more often a main goal for AJDI participants compared with nonparticipants (Table 6), and "time" as well as "capability of labour" were more often main constraints for nonparticipants compared with participants.

\section{External Stimuli}

The herd veterinarian was used most often as the source to obtain general information about new management strategies or technologies in both AJDI participants as well as nonparticipants, whereas the annual Western Canadian Dairy Seminar and communication by e-mail were least often used (Figure 2a). Gener- 
ally, few farmers stated that a particular source had a negative influence on their enrollment in the AJDI (Figure $2 \mathrm{~b}$ ), with $<3 \%$ of the farmers (exclusively nonparticipants) stating that the veterinarian or mastitis management workshops influenced them negatively and a maximum of $10 \%$ of farmers indicated that the breed association had a negative influence on their participation. For both groups, the herd veterinarian had the most positive influence to motivate enrollment. However, many of the information sources farmers used did not provide information on AJDI participation. In particular, more than one-third of producers were not

Table 3. Multivariable logistic regression model with intrinsic variables significantly related to participation in the Alberta Johne's Disease Initiative (AJDI) of 163 nonparticipating and 61 participating farms ${ }^{1}$

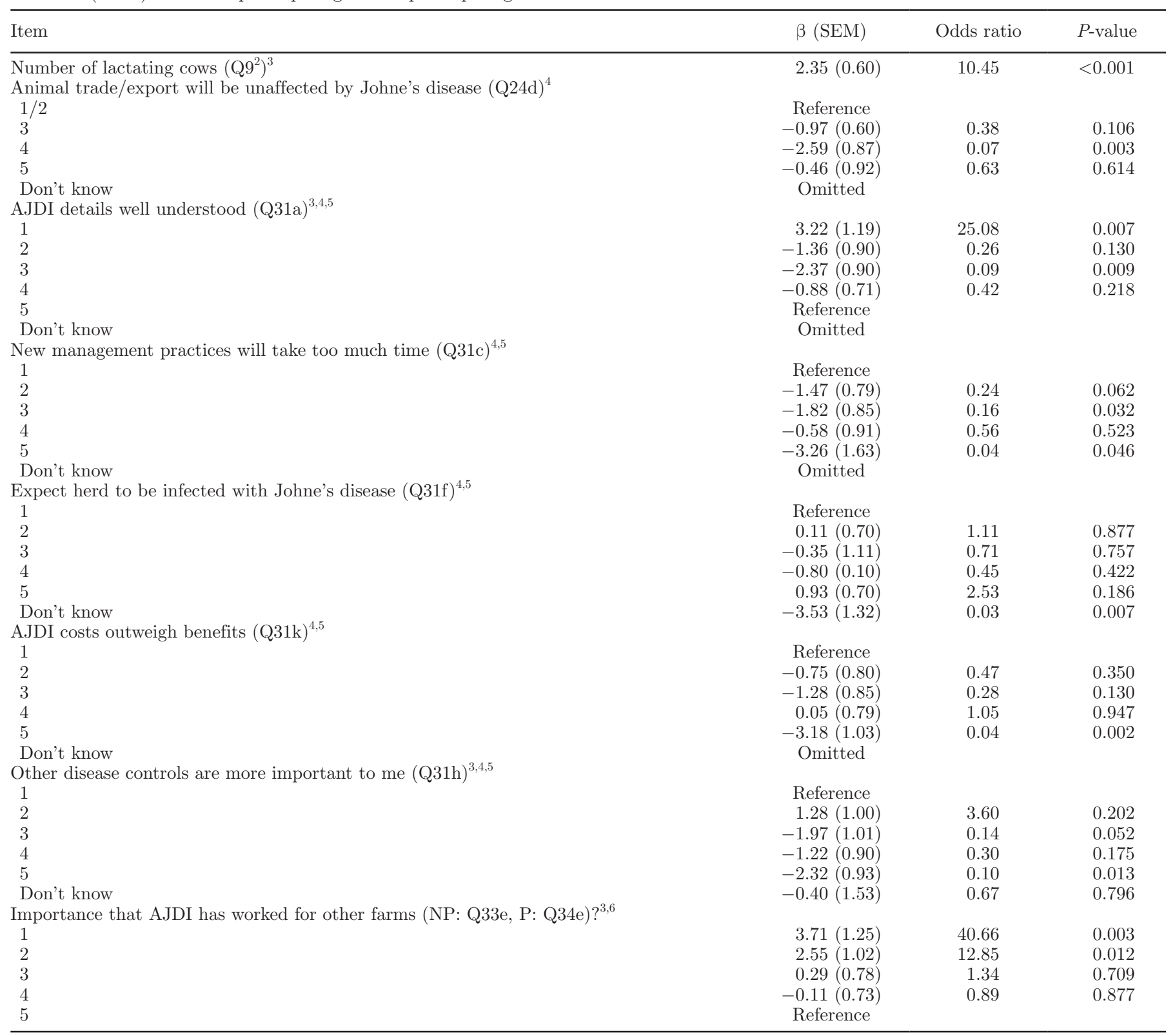

${ }^{1}$ Interviews were conducted between September 2012 and April 2014. Fourteen nonparticipants and 5 participants could not be included in the model because of a missing value for one or more of the explanatory variables.

${ }^{2}$ Number of question in survey.

${ }^{3}$ Variable selected for final model.

${ }^{4}$ Score: strongly disagree (1) to strongly agree (5).

${ }^{5}$ Participants were asked to answer retrospectively before their AJDI enrollment.

${ }^{6}$ Score: not important (1) to very important (5). 
Table 4. Ranking of main farm goals and constraints by 163 Alberta Johne's Disease Initiative nonparticipants (NP) and 61 participants (P) between September 2012 and April 2014 Rank, n (\%)

Item

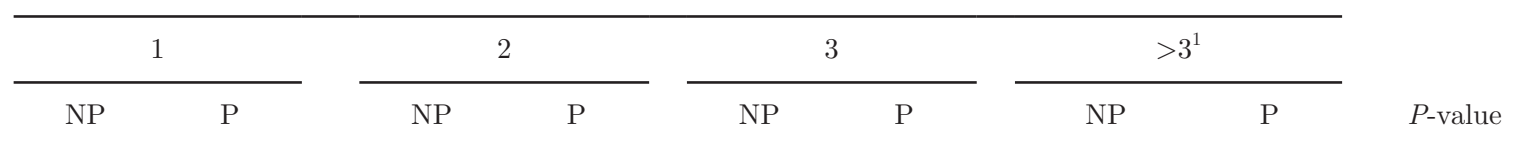

Goals $\left(\mathrm{Q}^{2}\right)$

Have higher milk production

Have increased herd fertility

Increase herd longevity

Expand

Have improved herd health

Meet quota

Increase net profit

Increase net profit
Spend more time with family and less time working

Constraints (Q8)

Time

Financial resources

Facilities

Land

Knowledge/skills

Availability of labor

Capability of labor

Quota management

$16(10)-5(8)$

$13(8) \quad 9(15)$

$25(15)$

$\begin{array}{lr}14(9) & 6(10) \\ 21 & 11(18)\end{array}$

$13(8)$

$9(15)$

\begin{tabular}{|c|c|c|c|c|c|}
\hline $13(8)$ & $9(15)$ & $25(15)$ & $4(7)$ & 109 (67) & $43(70)$ \\
\hline $24(15)$ & $9(15)$ & $24(15)$ & $9(15)$ & $101(62)$ & $37(61)$ \\
\hline
\end{tabular}

$25(15) \quad 4(7)$

$109(67)$

5 (3) $2(3)$

$\begin{array}{llll}28(17) & 11(18) & 21(13) & 9(15) \\ 11(7) & 2(3) & 9(6) & 2(3)\end{array}$

$101(62)$

$37(61)$

0.821

$\begin{array}{ll}31(19) & 10(16) \\ 18(11) & 1(2)\end{array}$

$\begin{array}{lccc}11(7) & 2(3) & 9(6) & 2(3) \\ 38(23) & 11(18) & 20(12) & 15(25)\end{array}$

$35(21) \quad 15(25)$

$\begin{array}{llll}11(7) & 2(3) & 8(5) & 1(2) \\ 22(14) & 8(13) & 27(17) & 7(11)\end{array}$

$138(85)$

$30(49)$

0.261
0.315

$\begin{array}{rr}35(21) & 15(25) \\ 19(12) & 8(13)\end{array}$

$74(45)$

$55(90)$

0.315

$126(77) \quad 57(93) \quad 0.045$

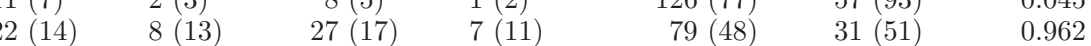

$50(31) \quad 17(28)$

$11(7) \quad 5(8)$

$79(48)$

$31(51)$

0.962

0.347

$34(21) \quad 11(18)$

$42(26) \quad 6(10)$

$17(10)$

$116(71)$

$39(64)$

0.024

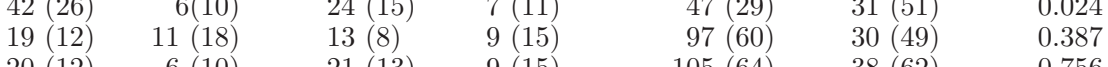

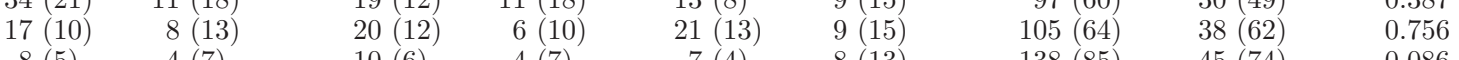

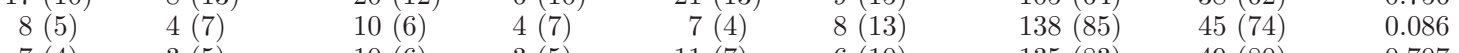

$\begin{array}{lr}\text { Quota management } & 10(6) \\ \text { Farm succession } & 7(4)\end{array}$

$\begin{array}{cl}7(4) & 3(5) \\ 19(12) & 6(10)\end{array}$

$7(4) \quad 3(5)$

$10(6) \quad 3(5) \quad 11(7) \quad 6(13)$

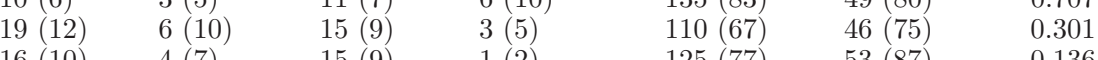

$\begin{array}{lll}135(83) & 49(80) & 0.086 \\ 110(67) & 46(75) & 0.307\end{array}$

${ }^{1}$ Not ranked among the first 3 goals or constraints.

${ }^{2}$ Number of question in survey. 
Table 5. Self-evaluated knowledge on specific Johne's disease (JD) aspects of 163 Alberta Johne's Disease Initiative nonparticipants (NP) and 61 participants (P) between September 2012 and April 2014

\begin{tabular}{|c|c|c|c|c|}
\hline \multirow[b]{2}{*}{ Item } & \multicolumn{3}{|c|}{ Producers, n (\%) } & \multirow[b]{2}{*}{$P$-value } \\
\hline & NP & $\mathrm{P}$ & Total & \\
\hline I know the clinical signs & $134(82)$ & $55(90)$ & $189(84)$ & 0.144 \\
\hline I know the general transmission of the disease & $129(79)$ & $59(97)$ & $188(84)$ & 0.001 \\
\hline I know the ages of high susceptibility & $100(61)$ & $47(77)$ & $147(66)$ & 0.028 \\
\hline I know the incubation time & $44(27)$ & $26(43)$ & $70(31)$ & 0.025 \\
\hline I know all of the vaccination/testing/control issues & $33(20)$ & $25(41)$ & $58(26)$ & 0.002 \\
\hline I know the current routes of JD research & $34(21)$ & $32(52)$ & $66(29)$ & $<0.001$ \\
\hline Average number of positive responses, mean (SD) & $5.21(2.03)$ & $6.46(1.74)$ & $5.55(2.03)$ & $<0.001$ \\
\hline
\end{tabular}

reached by the AJDI website, mastitis management workshops, breed associations, producer workshops, or DHI staff $(65,48,40,36$, and 34\%, respectively).

Multivariable logistic regression analysis revealed that AJDI nonparticipants used the telephone more often to get information about new management strategies or technologies compared with AJDI participants (Table 7). In contrast, participants used their veterinarian and workshops or seminars more often compared with nonparticipants. Participants scored AJDI mailouts more often as strong positive influence on AJDI enrollment (compared with nonparticipants who more often rated AJDI mail outs as noninfluential). Nonparticipants more often stated that they did not receive any information on AJDI participation from DHI than participants.

\section{Final Logistic Regression Model}

The major differences between AJDI nonparticipants and participants (based on the final logistic regression model) were that participating farmers had larger herds, a higher self-assessed knowledge of JD, a better understanding of AJDI details before participation, and used their herd veterinarian more often compared with nonparticipants (Table 8). In contrast, nonparticipants perceived time as a greater on-farm constraint and it was more important in their consideration about AJDI

Table 6. Logistic regression model comparing the main on-farm goals and constraints and self-assessed knowledge of Johne's disease (JD) of 163 Alberta Johne's Disease Initiative (AJDI) nonparticipants and 61 participants $^{1}$

\begin{tabular}{|c|c|c|c|}
\hline Item & $\beta(\mathrm{SEM})$ & Odds ratio & $P$-value \\
\hline Number of lactating cows $\left(\mathrm{Q9}^{2}\right)^{3}$ & $1.28(0.33)$ & 3.60 & $<0.001$ \\
\hline \multicolumn{4}{|l|}{ Herd health as main goal (Q7e) ${ }^{4}$} \\
\hline 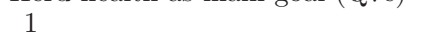 & $-0.55(0.50)$ & 0.58 & 0.276 \\
\hline 2 & $-0.32(0.50)$ & 0.72 & 0.500 \\
\hline 3 & $1.15(0.49)$ & 3.17 & 0.019 \\
\hline$>3$ & Reference & & \\
\hline \multicolumn{4}{|l|}{ Time as main constraint $(\mathrm{Q} 8 \mathrm{a})^{3,4}$} \\
\hline 1 & $-0.50(0.42)$ & 0.61 & 0.227 \\
\hline 2 & $-2.04(0.59)$ & 0.13 & 0.001 \\
\hline 3 & $-0.92(0.57)$ & 0.40 & 0.104 \\
\hline \multirow{2}{*}{\multicolumn{4}{|c|}{ Capability of labor as main constraint $(\mathrm{Q} 8 \mathrm{~g})^{4}$}} \\
\hline & & & \\
\hline 1 & $-0.32(0.78)$ & 0.73 & 0.683 \\
\hline $2 / 3$ & $-1.52(0.59)$ & 0.22 & 0.010 \\
\hline$>3$ & Reference & & \\
\hline Knowledge of JD $(\mathrm{Q} 19)^{3}$ & $0.36(0.10)$ & 1.43 & $<0.001$ \\
\hline
\end{tabular}

${ }^{1}$ Interviews were conducted between September 2012 and April 2014.

${ }^{2}$ Number of question in survey.

${ }^{3}$ Variable selected for final model.

${ }^{4}$ Rank (1 being the largest on-farm goal respectively constraint). 
a)

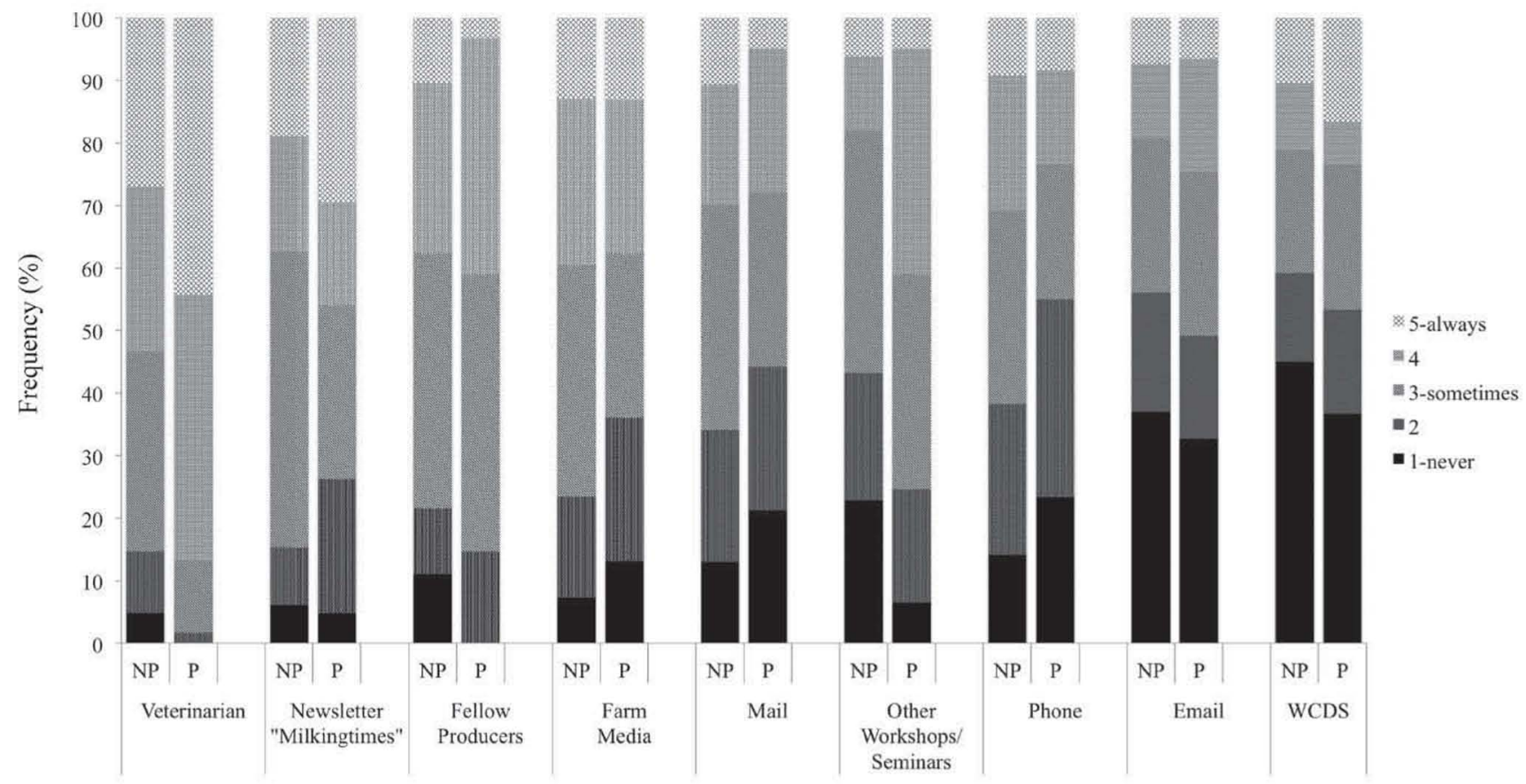

b)

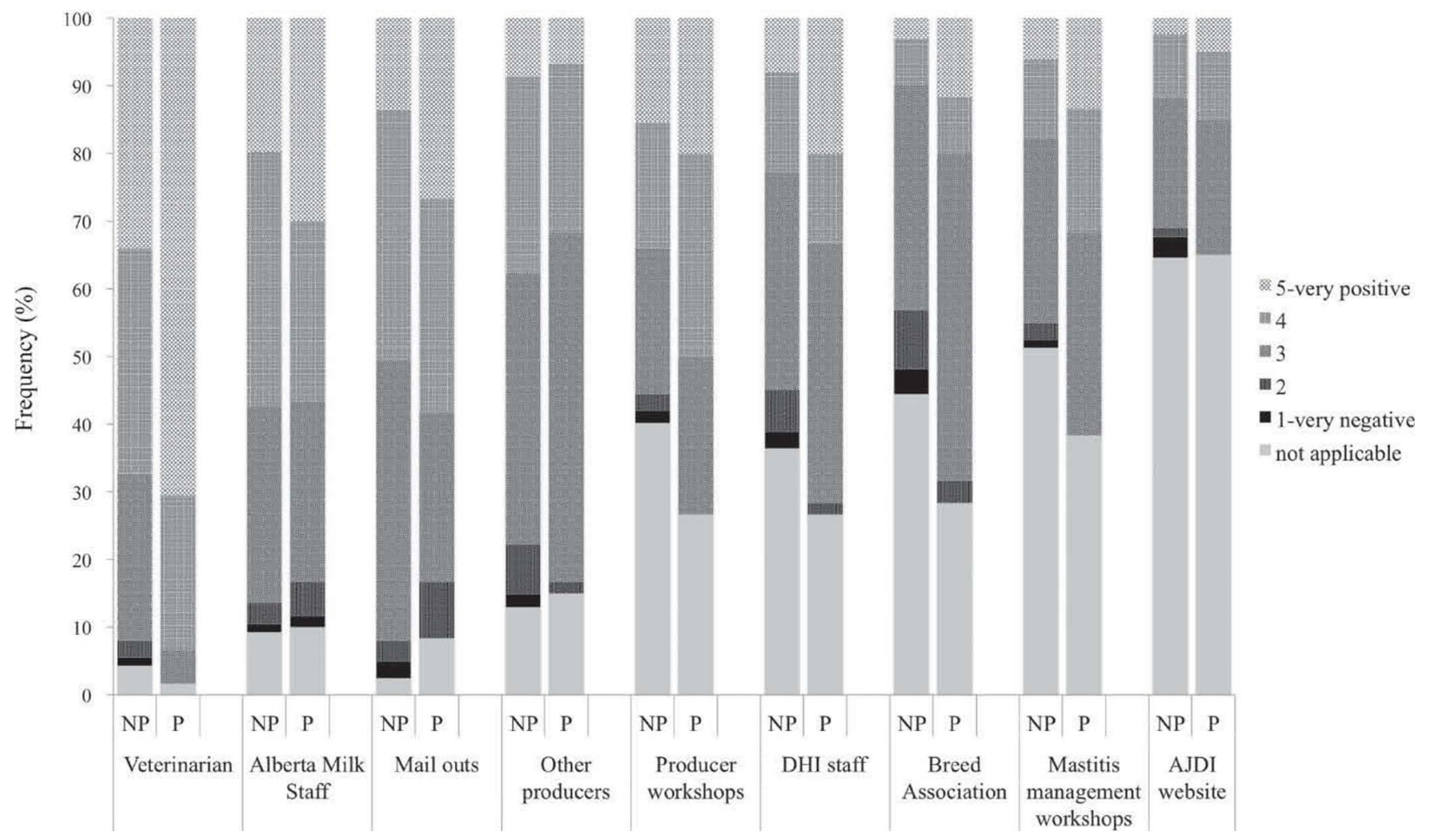

Figure 2. (a) Sources of information about new management practices and technologies used by 163 nonparticipants (NP) and 61 participants (P) in the Alberta Johne's Disease Initiative (AJDI). WCDS = Western Canadian Dairy Seminar. (b) Influence of extension tools on participation of $163 \mathrm{NP}$ and $61 \mathrm{P}$ in the AJDI. Interviews were conducted between September 2012 and April 2014. 
participation that the program has worked on other farms. No interaction terms remained in the final multivariable logistic regression model.

\section{DISCUSSION}

Control of JD is an example of targeted biosecurity on dairy farms to prevent disease introduction into the herd and transmission of the disease within the herd. In previous studies, larger livestock enterprises were more likely to have implemented higher biosecurity measures, due to better recognition of disease risk (Nöremark et al., 2010; Valeeva et al., 2011; Garforth et al., 2013). Similarly, AJDI participants had larger herds than nonparticipants.

Notwithstanding, AJDI participants were not more concerned about JD and evaluated its effects on the dairy industry similar to AJDI nonparticipants. Instead, individual on-farm considerations appeared to be the key factor for enrollment. Similarly, Hop et al. (2011) argued that factors related to individual farm performance were more important motivators than concern for consumer health and performance of the dairy sector. Therefore, it was not surprising that extrinsic factors such as financial and time considerations were noted as important impediments to enrolling in voluntary infectious disease control programs, and to improving biosecurity measures (Hop et al., 2011; Garforth et al., 2013). In the present study, nonparticipants did not consider finances a greater on-farm constraint compared with AJDI participants. However, they often strongly agreed with the statement that AJDI costs outweighed the benefits. Considering the producers did not have to pay for environmental testing and risk assessment when enrolled in the AJDI (Wolf et al., 2014b), this perception of nonparticipants could either arise from their lack of knowledge of AJDI details, or from their expectations that the recommended management changes would be too costly. Also, nonparticipants believed that management practices associated with the AJDI would take too much time; furthermore, they regarded time available for on-farm duties as a

Table 7. Multivariable logistic regression model comparing use of information sources by 163 Alberta Johne's Disease Initiative (AJDI) nonparticipants and 61 participants and influence of various sources on AJDI participation $^{1}$

\begin{tabular}{|c|c|c|c|}
\hline Item & $\beta(\mathrm{SEM})$ & Odds ratio & $P$-value \\
\hline Number of lactating cows $\left(\mathrm{Q9}^{2}\right)^{3}$ & $1.25(0.38)$ & 3.49 & 0.001 \\
\hline \multicolumn{4}{|l|}{ Phone $(\mathrm{Q} 5 \mathrm{i})^{4}$} \\
\hline 1 & Reference & & \\
\hline 2 & $-0.60(0.54)$ & 0.55 & 0.275 \\
\hline 3 & $-1.16(0.57)$ & 0.31 & 0.042 \\
\hline 4 & $-1.63(0.65)$ & 0.20 & 0.012 \\
\hline 5 & $-2.07(0.78)$ & 0.13 & 0.008 \\
\hline \multicolumn{4}{|l|}{ Veterinarian $(\mathrm{Q} 5 \mathrm{~b})^{3,4}$} \\
\hline $1 / 2 / 3$ & $-1.71(0.51)$ & 0.18 & 0.001 \\
\hline 4 & $-0.27(0.44)$ & 0.76 & 0.538 \\
\hline \multirow{2}{*}{\multicolumn{4}{|c|}{ Seminars and workshops $(\mathrm{Q} 5 \mathrm{~d})^{3,4}$}} \\
\hline & & & \\
\hline $1 / 2$ & $-1.06(0.49)$ & 0.35 & 0.029 \\
\hline 3 & $-1.29(0.48)$ & 0.28 & 0.007 \\
\hline \multirow{2}{*}{\multicolumn{4}{|c|}{$\begin{array}{l}\text { 4/5 } \\
\text { AJDI mail-outs }(\mathrm{Q} 35 \mathrm{a})^{5}\end{array}$}} \\
\hline & & & \\
\hline $\mathrm{N} / \mathrm{A}^{6}$ & $0.96(0.85)$ & 2.60 & 0.260 \\
\hline $1 / 2$ & $-0.80(0.82)$ & 0.45 & 0.333 \\
\hline 3 & $-1.40(0.57)$ & 0.25 & 0.014 \\
\hline 4 & $-0.61(0.55)$ & 0.54 & 0.270 \\
\hline 5 & Reference & & \\
\hline \multicolumn{4}{|l|}{ DHI $(\mathrm{Q} 35 \mathrm{e})^{5}$} \\
\hline $1 / 2 / 3$ & Reference & & \\
\hline 4 & $-0.40(0.58)$ & 0.67 & 0.489 \\
\hline 5 & $0.36(0.59)$ & 1.44 & 0.534 \\
\hline $\mathrm{N} / \mathrm{A}$ & $-1.00(0.49)$ & 0.37 & 0.041 \\
\hline
\end{tabular}

${ }^{1}$ Interviews were conducted between September 2012 and April 2014. Three nonparticipants and 2 participants could not be included in the model because of a missing value for one or more of the explanatory variables.

${ }^{2}$ Number of question in survey.

${ }^{3}$ Variable selected for final model.

${ }^{4}$ Score: never (1) to always (5).

${ }^{5}$ Score: negative influence (1) to positive influence (5).

${ }^{6}$ Not applicable. 
Table 8. Final multivariable logistic regression model of factors associated with Alberta Johne's Disease Initiative (AJDI) participation comparing 163 nonparticipants (NP) and 61 participants $(\mathrm{P})^{1}$

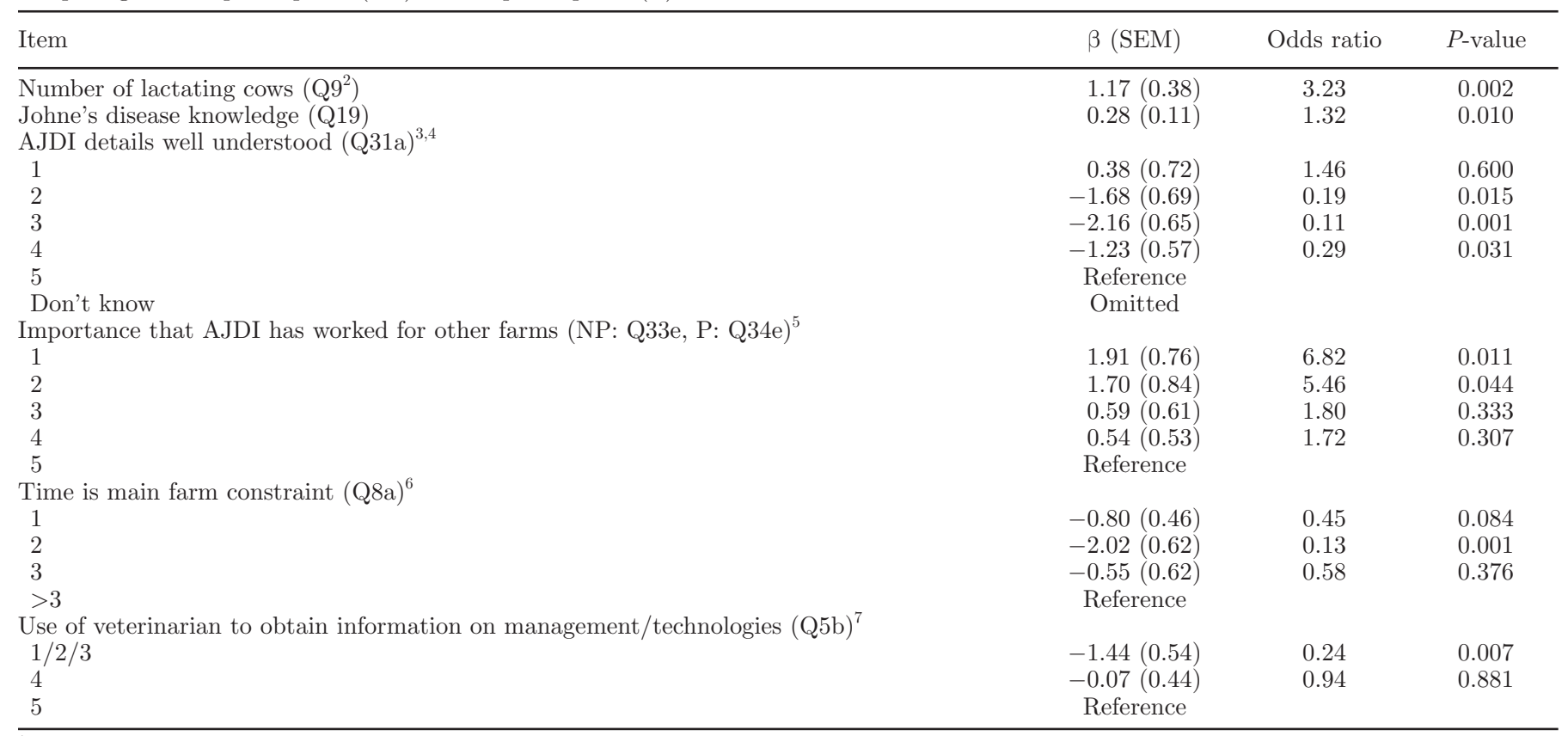

${ }^{1}$ Interviews were conducted between September 2012 and April 2014. Fourteen nonparticipants and 5 participants could not be included in the model because of a missing value for one or more of the explanatory variables.

${ }^{2}$ Number of question in survey.

${ }^{3}$ Score: strongly disagree (1) to strongly agree (5).

${ }^{4}$ Participants were asked to answer retrospectively before their AJDI enrollment.

${ }^{5}$ Score: not important (1) to very important (5).

${ }^{6}$ Rank (1 being the largest on-farm constraint).

${ }^{7}$ Score: never (1) to always (5).

greater constraint. Although some recommended JD control strategies might require considerable time, cost, or both, often small changes can decrease the risk of MAP transmission. When communicating principles of the AJDI to nonparticipating farmers, it is important to highlight that the veterinarian is advised to take farmers' individual goals and constraints into account and develop feasible changes in collaboration with the farmer. This individual approach aims to make JD control more attainable for farmers by selecting specific management strategies from an extensive (and potentially overwhelming) pool of recommended JD control measures. Additionally, for farmers that weigh the expected benefits of JD control against time or financial impact, it should be highlighted that these control strategies can also decrease other fecal-orally transmitted diseases (McKenna et al., 2006) and reduce economic losses. This argument might facilitate enrollment, especially because improved herd health and increased net profit were among the most important onfarm goals for nonparticipants. Similar to participants, nonparticipants also aimed for increased herd longevity and improved herd fertility. Therefore, it can be argued that it is often not the goal itself that differed between groups, although participants seemed to consider the AJDI program beneficial to achieve these goals.

Consistent with findings in a Dutch JD program (Hop et al., 2011), knowledge about JD aspects was positively associated with participation in the control program. Farmers that are aware of potential losses associated with the disease are probably more willing to take action to prevent transmission; in contrast, lack of knowledge could impede uptake of favorable management strategies (Alarcon et al., 2014). However, it cannot be determined whether AJDI participants gained additional knowledge by participation in the program.

Knowledge and awareness of a disease are important, albeit not sufficient for implementation of prevention strategies. In that regard, perceived efficiency and practicability are also important considerations for producers (Jansen and Lam, 2012; Garforth et al., 2013). Nonparticipants seemed to be more deferring about the AJDI and it was more important to them that the program has worked on other farms before they consider enrollment. Seemingly, these producers were hesitant to enroll and invest money and time be- 
fore they had sufficient self-perceived evidence that the AJDI was successful in limiting JD on other producers' farms. However, due to the chronic nature of the disease, the effect of implemented management changes may take years to reduce JD prevalence. Therefore, it is not feasible to wait for definitive results from AJDI participants to motivate nonparticipants. Additionally, the program has more chance of success if the vast majority of farmers participate. To facilitate success of the AJDI, nonparticipants have to overcome their wait-and-see mindset and stakeholders need to promote proactive enrollment. It is therefore fundamental to not only inform farmers about JD control strategies but also highlight that the AJDI was developed based on latest knowledge of MAP transmission and that similar JD control programs in North America have already decreased MAP prevalence in participating herds (Ferrouillet et al., 2009; Collins et al., 2010; Sorge et al., 2011). Currently, it is not known whether veterinary practitioners have this information and to what extent they educate clients about the success of other control programs. To alter farmers' negative perceptions and motivate proactive enrollment, successful communication is key. Many studies concluded that farmers perceived veterinarians as a reliable and credible source with regards to disease risk management (Gunn et al., 2008; Jansen and Lam, 2012; Brennan and Christley, 2013; Garforth et al., 2013). Furthermore, the current study demonstrated that participants used their herd veterinarian more often to get information about new management practices and technologies. Considering that discussions with their veterinarian can alter existing ideas and attitudes, and may initiate farmers to changes in management (Lam et al., 2011; Jansen and Lam, 2012), it is likely that veterinarians have an important role in promoting AJDI participation.

In addition to getting information from their veterinarian, AJDI participants were also more likely than nonparticipants to use workshops and seminars as source of information regarding new management strategies. Perhaps the AJDI with its interactive nature and engagement of the herd veterinarian was more consistent with farmers that liked to be involved through discussions with their veterinarian or in workshops. In contrast, nonparticipants more often used the telephone to receive information on management or technologies. These different learning preferences should be accounted for when communicating the AJDI to producers, as it has been argued that efficacy of communication strategies can be improved when aligned with learning preferences (Fleming and Baume, 2006; Hawk and Shah, 2007). Therefore, it would be advisable to also promote the AJDI via telephone.
Similarly to the findings of this study, previous studies reported that farmers' received information about farm management and biosecurity from a variety of sources, although preference for the delivery of information varied (Jansen et al., 2010; Russell and Bewley, 2011). It is therefore crucial to engage all extension tools that may inform farmers' decision making and ensure that these tools consistently articulate the same message, thereby avoiding confusion from contradictory influences (Moore et al., 2008). Farmers in this study hardly perceived the influence of any of the communication channels used as negative. However, it appeared that many farmers did not receive any influential messages on AJDI enrollment from a variety of sources. Presumably, this was a missed opportunity to reach these producers. For example, in a similar JD control program in Ontario, Canada, participation rates varied among counties and the authors suggested that the observed variations were partly explained by differences in engagement with DHI technicians with regard to motivating farmers to enroll (Pieper et al., 2015).

Temporal associations between AJDI participation and presented results could not always be established. This was especially true for assessment of JD knowledge because it cannot be excluded that farmers gained additional knowledge through participation in the AJDI. Also, data collected in this study did not consist of objective, proven knowledge, but rather what the individual farmer thinks $\mathrm{s} /$ he knows in relation to the disease, which might vary from actual knowledge and lead to misclassification bias. Interviewer bias could have been introduced due to the personal nature of face-toface interviews. Furthermore, involvement of different interviewers could have led to differential responses of the farmers. However, to reduce these potential sources for misclassification bias, fixed-wording questions were applied.

It is possible that the interviewed farmers differed systematically from the farmers that refused to take part in the study. However, this selection bias is likely small, because high percentages of the contacted farmers agreed to be surveyed. List-wise deletion of subjects with missing data could also have led to selection bias. However, $<9 \%$ of the data were missing in any given model and the effect was therefore assumed to be small.

Farmers eligible for the study comprised the vast majority of Alberta dairy farms. Therefore, it can be assumed that the results of this study were representative for most dairy farmers in Alberta. It was noteworthy that Alberta dairy producers shared similarities with other farmers around the world. In particular, use of various information sources with preference for their veterinarian and a focus on individual-farm perfor- 
mance has been reported not only for dairy producers, but also in other livestock farmers (Jansen et al., 2010; Hop et al., 2011; Garforth, 2012). Therefore, this study provides valuable information regarding enrollment of livestock farmers in voluntary disease programs, and possibly other programs, in countries with a developed livestock industry.

\section{CONCLUSIONS}

Nonparticipants in the AJDI were less informed about JD and the AJDI than participants. Therefore, the first step to enhance enrollment is to educate them about the disease and benefits of the AJDI. If the goal is for nonparticipants to change their wait-and-see mindset, it is important that they believe in the potential of the AJDI. Therefore, benefits of a structured province-wide approach for JD control need to be emphasized and barriers for enrollment need to be reduced. In communication with nonparticipants, it is key to emphasize that even minor management changes can decrease the risk of JD transmission, and that these changes are not necessarily costly nor time consuming. Furthermore, farmers might be more motivated to improve on-farm JD control if they know that these management changes can also decrease transmission of other fecal-orally transmitted diseases. The veterinarian seemed to be the ideal mediator to motivate producers, although the message should be brought forward consistently by articulating a congruent message through all potentially influential sources. Highlighting AJDI benefits, addressing farmers' individual concerns, and applying efficient extension tools is crucial and should motivate farmers to enroll more proactively.

\section{ACKNOWLEDGMENTS}

The authors thank the producer organization Alberta Milk (Edmonton, AB, Canada) for their assistance with farm recruitment and sample collection. Data collection for this study was funded by Alberta Milk and the Alberta Livestock and Meat Agency Ltd. (ALMA, Edmonton, AB, Canada). This study was part of the Industrial Research Chair in Infectious Diseases of Dairy Cattle, funded by Canada's Natural Sciences and Engineering Research Council (NSERC) Industrial Research Chair Program (Ottawa, ON, Canada), with industry contributions from Alberta Milk (Edmonton, AB, Canada), the Dairy Farmers of Canada (Ottawa, ON, Canada), Westgen Endowment Fund (Milner, BC, Canada), the BC Dairy Association (Burnaby, BC, Canada), Canadian Dairy Network (Guelph, ON, Canada), CanWest DHI (Guelph, ON, Canada), and Dairy Farmers of Manitoba (Winnipeg, MN, Canada).

\section{REFERENCES}

Ajzen, I. 1991. The theory of planned behavior. Organ. Behav. Hum. Dec. 50:179-211.

Alarcon, P., B. Wieland, A. L. Mateus, and C. Dewberry. 2014. Pig farmers' perceptions, attitudes, influences and management of information in the decision-making process for disease control. Prev. Vet. Med. 116:223-242.

Barkema, H. W., S. Hendrick, J. M. De Buck, S. Ghosh, G. G. Kaplan, and K. P. Rioux. 2011. Crohn's disease in humans and Johne's disease in cattle - Linked diseases? Pages 197-213 in Zoonotic Pathogens in the Food Chain. D. Krause and S. Hendrick, ed. CAB International, Wallingford, UK.

Barkema, H. W., K. Orsel, A. Koets, V. P. Rutten, J. Bannantine, G. P. Keefe, D. F. Kelton, S. J. Wells, R. Whittington, C. G. Mackintosh, E. J. Manning, M. F. Weber, J. P. Kastelic, and J. De Buck. 2014. Bottlenecks in the prevention and control of Mycobacterium avium ssp. paratuberculosis infection. Pages 111-113 in Proc. 12th International Colloquium on Paratuberculosis, Parma, Italy.

Brennan, M. L., and R. M. Christley. 2013. Cattle producers' perceptions of biosecurity. BMC Vet. Res. 9:71.

Coleman, M. T., and R. H. Pasternak. 2012. Effective strategies for behavior change. Prim. Care 39:281-305.

Collins, M. T., V. Eggleston, and E. J. Manning. 2010. Successful control of Johne's disease in nine dairy herds: results of a six-year field trial. J. Dairy Sci. 93:1638-1643.

Dohoo, I. R., C. Ducrot, C. Fourichon, A. Donald, and D. Hurnik. 1997. An overview of techniques for dealing with large numbers of independent variables in epidemiologic studies. Prev. Vet. Med. 29:221-239.

Ellis-Iversen, J., A. J. C. Cook, E. Watson, M. Nielen, L. Larkin, M. Wooldridge, and H. Hogeveen. 2010. Perceptions, circumstances and motivators that influence implementation of zoonotic control programs on cattle farms. Prev. Vet. Med. 93:276-285.

Ferrouillet, C., S. J. Wells, W. L. Hartmann, S. M. Godden, and J Carrier. 2009. Decrease of Johne's disease prevalence and incidence in six Minnesota, USA, dairy cattle herds on a long-term management program. Prev. Vet. Med. 88:128-137.

Field, A. 2005. Discovering Statistics Using SPSS. 2nd ed. 2nd ed. Sage Publications Ltd., London, UK.

Fleming, N., and D. Baume. 2006. Learning styles again: VARKing up the right tree! Educat. Dev. 7:4-7.

Garforth, C. J. 2012. Effective communication to improve udder health: can social science help? Pages 55-66 in Udder Health and Communication. H. Hogeveen and T. J. G. M. Lam, ed. Wageningen Academic Publishers, Wageningen, the Netherlands.

Garforth, C. J., A. P. Bailey, and R. B. Tranter. 2013. Farmers' attitudes to disease risk management in England: A comparative analysis of sheep and pig farmers. Prev. Vet. Med. 110:456-466.

Groenendaal, H., and F. J. Zagmutt. 2008. Scenario analysis of changes in consumption of dairy products caused by a hypothetical causal link between Mycobacterium avium subspecies paratuberculosis and Crohn's disease. J. Dairy Sci. 91:3245-3258.

Gunn, G. J., C. Heffernan, M. Hall, A. McLeod, and M. Hovi. 2008 Measuring and comparing constraints to improved biosecurity amongst GB farmers, veterinarians and the auxiliary industries. Prev. Vet. Med. 84:310-323.

Hawk, T. F., and A. J. Shah. 2007. Using learning style instruments to enhance student learning. Decision Sciences Journal of Innovative Education 5:1-19.

Hop, G. E., A. G. J. Velthuis, and K. Frankena. 2011. Assessing Dutch farmers' incentives to join a voluntary Johne's disease programme. NJAS-Wagen. J. Life Sci. 58:57-64.

Jansen, J., and T. J. G. M. Lam. 2012. The role of communication in improving udder health. Vet. Clin. North Am. Food Anim. Pract. 28:363-379.

Jansen, J., C. D. M. Steuten, R. J. Renes, N. Aarts, and T. J. G. M. Lam. 2010. Debunking the myth of the hard-to-reach farmer: Effective communication on udder health. J. Dairy Sci. 93:1296-1306

Janz, N., and M. H. Becker. 1984. The health belief model: A decade later. Health Educ. Q. 11:1-47. 
Kaiser, H. F. 1960. The application of electronic computers to factor analysis. Educ. Psychol. Meas. 20:141-151.

Lam, T. J. G. M., J. Jansen, B. H. P. Van den Borne, R. J. Renes, and $\mathrm{H}$. Hogeveen. 2011. What veterinarians need to know about communication to optimise their role as advisor on udder health in dairy herds. N. Z. Vet. J. 59:8-15.

Likert, R., and S. P. Hayes. 1961. Some applications of behavioural research. UNESCO Publications Center, New York, NY.

McKenna, S. L., G. P. Keefe, A. Tiwari, J. VanLeeuwen, and H. W. Barkema. 2006. Johne's disease in Canada part II: Disease impacts, risk factors, and control programs for dairy producers. Can. Vet. J. 47:1089-1099.

Moore, D. A., M. L. Merryman, M. L. Hartman, and D. J. Klingborg. 2008. Comparison of published recommendations regarding biosecurity practices for various production animal species and classes. J. Am. Vet. Med. Assoc. 233:249-256.

Nöremark, M., J. Frossling, and S. S. Lewerin. 2010. Application of routines that contribute to on-farm biosecurity as reported by Swedish livestock farmers. Transbound. Emerg. Dis. 57:225-236.

Panter-Brick, C., S. E. Clarke, H. Lomas, M. Pinder, and S. W. Lindsay. 2006. Culturally compelling strategies for behaviour change: A social ecology model and case study in malaria prevention. Soc. Sci. Med. 62:2810-2825.

Pieper, L., T. J. DeVries, U. S. Sorge, A. Godkin, K. J. Hand, N. R. Perkins, J. Imada, and D. Kelton. 2015. Variability in Risk Assessment and Management Plan (RAMP) scores completed as part of the Ontario Johne's Education and Management Assistance Program (2010-2013). J. Dairy Sci. 98:2419-2426.
Russell, R. A., and J. M. Bewley. 2011. Producer assessment of dairy extension programming in Kentucky. J. Dairy Sci. 94:2637-2647.

Sorge, U. S., K. Lissemore, A. Godkin, J. Jansen, S. Hendrick, S. Wells, and D. F. Kelton. 2011. Changes in management practices and apparent prevalence on Canadian dairy farms participating in a voluntary risk assessment-based Johne's disease control program. J. Dairy Sci. 94:5227-5237.

Sweeney, R. W., M. T. Collins, A. P. Koets, S. M. McGuirk, and A. J. Roussel. 2012. Paratuberculosis (Johne's disease) in cattle and other susceptible species. J. Vet. Intern. Med. 26:1239-1250.

Tiwari, A., J. A. VanLeeuwen, S. L. McKenna, G. P. Keefe, and H. W. Barkema. 2006. Johne's disease in Canada Part I: Clinical symptoms, pathophysiology, diagnosis, and prevalence in dairy herds. Can. Vet. J. 47:874-882

Valeeva, N. I., M. A. van Asseldonk, and G. B. Backus. 2011. Perceived risk and strategy efficacy as motivators of risk management strategy adoption to prevent animal diseases in pig farming. Prev. Vet. Med. 102:284-295.

Wolf, R., H. W. Barkema, J. De Buck, M. Slomp, J. Flaig, D. Haupstein, C. Pickel, and K. Orsel. 2014a. High herd-level prevalence of Mycobacterium avium subspecies paratuberculosis in Western Canadian dairy farms, based on environmental sampling. J. Dairy Sci. 97:6250-6259.

Wolf, R., F. Clement, H. W. Barkema, and K. Orsel. 2014b. Economic evaluation of participation in a voluntary Johne's disease prevention and control program from a farmer's perspective- The Alberta Johne's Disease Initiative. J. Dairy Sci. 97:2822-2834. 